Conference Proceedings Paper

\title{
Effects of Olive Cultivation Characteristics on Land Snail Community Patterns in Crete, Greece
}

\author{
Elisavet Georgopoulou ${ }^{1, *}$, Vasileios Gkisakis ${ }^{1}$ and Emannouil Kabourakis ${ }^{1}$ \\ 1 Olive and Agroecological Production Systems Lab (EOPS), Department of Agriculture, Hellenic \\ Mediterranean University (HMU), Greece \\ * Correspondence: georgelisavet@yahoo.gr; Tel.: +30 6937145410
}

\begin{abstract}
Olive agroecosystems are of great agricultural, environmental, cultural and economic importance for the Mediterranean. In the island of Crete (Greece) olive orchards are the most common cultivation, occupying $20 \%$ of the total land area. Patterns of invertebrate biodiversity of olive cultivation have been associated with farming systems, the agro-ecological zones of cultivation and landscape attributes. Terrestrial snails of 16 olive orchards under two different farming systems (organic and conventional) located in two different agro-ecological zones (plain and hilly) were studied in the Messara plain, south Crete. Linear models and Mantel tests were used to evaluate the effect of different factors on land snail richness and composition, respectively. Species richness of terrestrial snails was higher in hilly olive orchards regardless of the farming systems. Species richness was explained by landscape attributes (olive orchard area, isolation, slope and anthropogenic impact), while species composition was only partly associated with landscape characteristics. Preliminary results indicate distinct community patterns of terrestrial snails in olive orchards in the Messara plain. Landscape characteristics are important factors affecting snail biodiversity of olive orchards. Terrestrial snails are highlighted as potential indicators for studying the impact of olive orchard management on biodiversity.
\end{abstract}

Keywords: invertebrate assemblages; olive orchards; species richness; species composition; agroecology

\section{Introduction}

Agricultural land covers ca. 40\% of the Earth's surface [1], hosting a plethora of animal and plant species. As with other environments, agroecosystems and their biodiversity face serious threats [2]. Lately, scientists have observed a dramatic decrease in species related to agroecosystems (e.g. [3]). Among the main threats to agroecosystems that can cause species loss is agricultural intensification, habitat fragmentation in isolated patches and homogenization of the agricultural landscape [4-6]. Loss of biodiversity, in turn, can lead to loss of agroecosystem services, e.g. loss of species that provide biological pest control, could lead to the degradation of the quality and the quantity of the agricultural production.

Mediterranean countries, like Greece, are characterized by olive cultivation across a variety of landscapes and agroecological zones and under different farming systems. Nowadays, olive cultivation frequently follows a conventional and intensive agricultural protocol, in order to increase profitability, this is the case also in Crete, with considerable impact on biodiversity [7-11]. Nevertheless, only a limited number of studies have been conducted regarding the biodiversity of Mediterranean olive orchards so far [9-11, 12, 13].

Land snails in agroecosystems have been considerably less studied (e.g. [5, 14]) in comparison to other animal groups (e.g. birds). Nonetheless, land snails comprise a promising bio-indicator for 
monitoring agroecosystem and farmland biodiversity in general (e.g. [14, 15]). In Crete, more than 100 species have been found, many of which are endemic to Crete and adjacent islands [16].

The present study aims a) to research and record, for the first time, the land snail biodiversity in olive orchards in Crete under different farming systems (organic and conventional) and distributed in two agroecological zones (hilly and plain), and b) to evaluate the effect of landscape attributes related to habitat fragmentation, habitat isolation and anthropogenic impact on land snail biodiversity. So far, studies on olive orchard biodiversity usually concern arthropods or birds (e.g. [9-11]). However, the study of multiple groups may offer safer conclusions regarding the state of agroecosystems as different plant and animal groups may respond differently to biotic and abiotic environmental attributes $[5,6,14,17,18]$.

\section{Materials and Methods}

Field Sampling

The study took place in 16 olive orchards planted with Koroneiki cultivar and located in two different agroecological zones at western Messara plain in southern Crete, Greece. Two different farming systems were applied on the olive orchards, i.e. conventional and organic. Seven conventional orchards follow the corresponding description in the EU Common Agricultural Policy framework and nine organic orchards follow EU legislation on organic farming [(EC) 834/2007]. The selection of orchards was based on previous research carried out in the area $[7,8]$. The orchards were equally distributed in the two different agroecological zones, i.e. plain and hilly, differentiated upon elevation, terrain, abiotic (soil type and fertility, rainfall, temperature, humidity), and biotic environment (fauna and flora), and the intensity of management applied in the olive orchards.

Collection of land snails took place between October 2019 and November 2020. Land snails were collected by hand along transects, from predefined $1 \mathrm{sqm}^{2}$ patches and from all potential microhabitats inside the orchards. Such microhabitats include the area under the olive trees, rocks or rock walls, uncultivated parts inside the orchards etc. Snails were identified at the species level using updated taxonomic keys (e.g. [16]).

\section{Statistical analyses}

Differences in species richness between the different farming systems and the different agroecological zones were tested using a Student's t-test. Linear mixed effects models and linear models were used to explain the effect of landscape attributes on species richness. Prior to model building, species richness and all the predictors were $\log _{10}$-transformed to follow a normal distribution. A visual inspection of Q-Q plots was used for the assessment of the normality assumptions. The Variance Inflation Factor (VIF) was used to test for collinearity among the predictors. Highly collinear variables, i.e. VIF values $>10$ [19], were excluded from further analyses as they could bias the models' estimates. Remaining variables included orchard area as a proxy for habitat amount (sensu [5]), distance to nearest natural grassland and sclerophyllous vegetation as a proxy for habitat isolation, closest distance to urban structures and closest distance to the road network as proxies for anthropogenic impact. Other landscape characteristic included in the analyses were mean orchard altitude and mean orchard slope. Natural grassland and sclerophyllous vegetation refer to Corine Land Cover (CLC) classes (https://land.copernicus.eu/pan-european/corine-land-cover). The distances from natural grassland, sclerophyllous vegetation and discontinuous urban fabric (i.e. urban structures) were calculated using the 'near' tool in ArcMap v10.7.1.

Eight linear and linear mixed effects models were used to assess the effect of landscape attributes on land snail species richness. The eight models had different combinations of parameters and random effects in order to test for a potential effect of management practice and/or agro-ecological zone on species richness. Models were built using the commands ' $1 \mathrm{~m}$ ' and 'Imer' of the 'lme4' $\mathrm{R}$ package [20]. Models were compared via Akaike Information Criterion (AIC). Models differed significantly when $\triangle \mathrm{AIC}>2$ [21]. 
Variation in land snail composition among the olive orchards was assessed using the Jaccard dissimilarity indices, namely $b_{j a c}, b_{j t u}$ and $b_{j n e}$. Compositional dissimilarity is partitioned into dissimilarity resulting from species replacement without the influence of species richness and dissimilarity resulting from species loss [21,22]. bjac equals to dissimilarity due to species replacement between olive orchards ( $b_{j t u}$ ) and due to species loss ( $\left.b_{j n e}\right)$ [22]. The $R$ package betapart v. 1.5.2 [23] was used to calculate the dissimilarity indices. Mantel and partial Mantel tests were used to explore compositional dissimilarity patterns among the olive orchards in relation to the geographic and environmental distance between them. Environmental distance was expressed as a set of landscape characteristics, i.e. orchard area, mean orchard altitude, mean orchard slope, distance to nearest natural grassland and sclerophyllous vegetation, closest distance to urban structures and closest distance to the road network. The environmental distance matrix was created using Euclidean distances. The geographic distance matrix was produced in ArcGIS using the tool 'Generate Near Table', which calculates the geographic distance between each pair of olive orchards. Mantel and partial Mantel tests were generated using the R package vegan v. 2.5-7 [24].

\section{Results}

In total, 18 species were identified belonging to 17 genera and 8 families. The species Cornu aspersum (O.F. Muller, 1774), Cantareus apertus (Born, 1778) and Eobania vermiculata (O.F. Muller, 1774) were found in all olive orchards, and the species Pseudoxerophila bathytera (Westerlund \& Blanc, 1879) was found only in one olive orchard. Mean species richness was 9.6 \pm 2.16 . Average species richness in hilly orchards was significantly higher than in plain olive orchards $(p=0.0062)$. There was no significant difference between species richness in conventional and organic olive orchards $(p=0.76)$ (Figure 1).

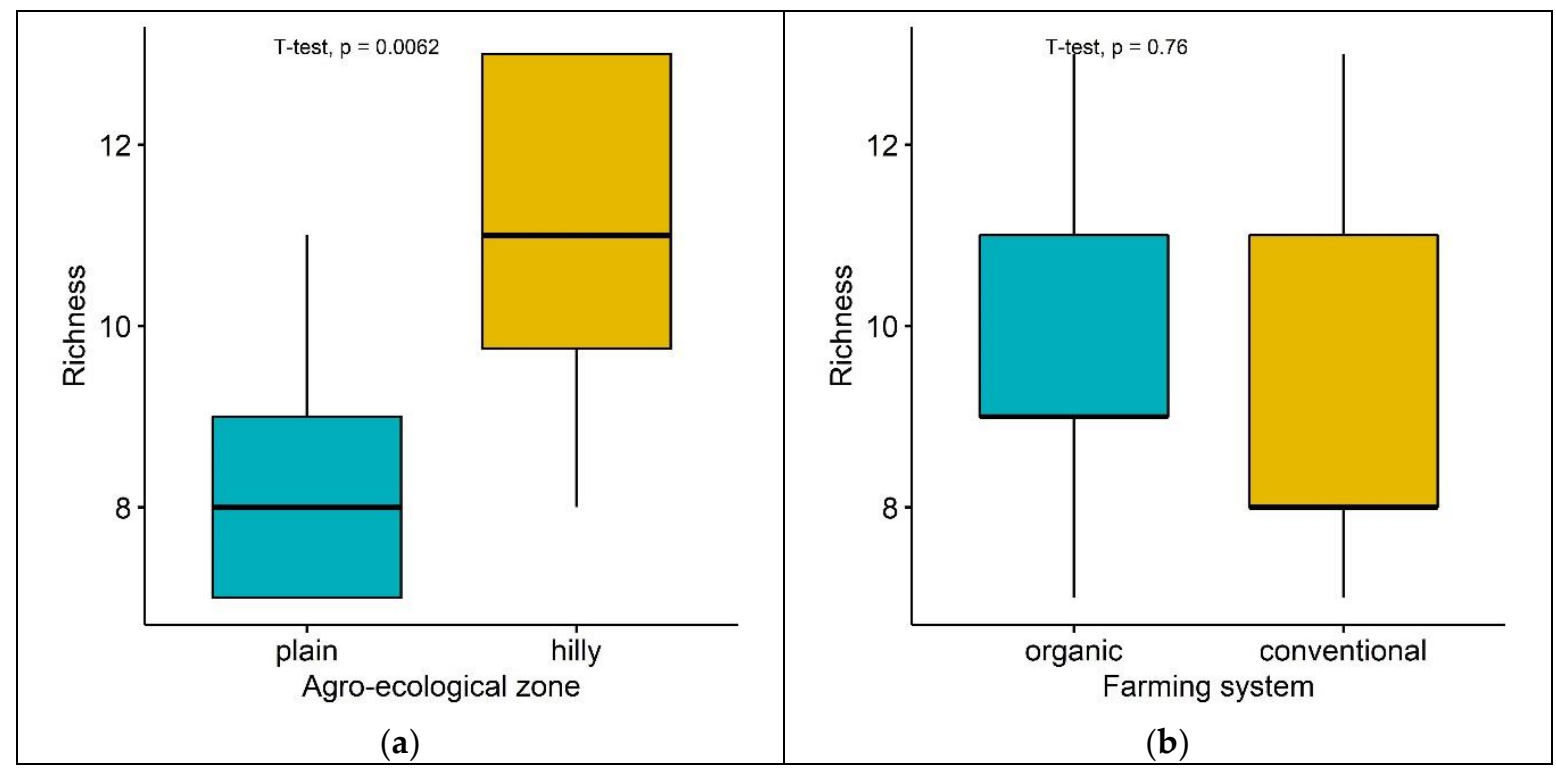

Figure 1. Boxplots showing differences in species richness of the Cretan olive orchards: (a) Average species richness varied significantly between agro-ecological zones, i.e. plain and hilly; (b) Average species richness did not vary significantly between farming systems, i.e. organic and conventional.

The best linear model $(\triangle \mathrm{AIC}>2)$ explained very well variation in species richness of the olive orchards $\left(F=12.53, p=0.002, R_{a d j .}^{2}=0.8602\right)($ Table 1$)$. The farming system and/or the agro-ecological zone did not improve the model when used as random factors (Appendix A). Species richness increased with orchard area and mean altitude, as well as, when orchards were closer to urban constructions and to natural grassland and sclerophyllous vegetation.

Table 1. Results of the best linear model $(\triangle \mathrm{AIC}>2)$. Significant variables are in bold. 


\begin{tabular}{cccccc}
\hline $\boldsymbol{R}^{2}{ }_{\text {adj. }}$ & $\boldsymbol{P}^{\mathbf{1}}$ & $\boldsymbol{\Delta} \mathrm{AIC}^{2}$ & \multicolumn{1}{c}{ Variables $^{3}$} & Est. $^{\mathbf{4}}$ & $\boldsymbol{P}_{\text {var. }}{ }^{\mathbf{2}}$ \\
\hline 0.8602 & 0.002 & 3.79 & Farming system - organic & 0.03632 & 0.12 \\
& & & Agro-ecological zone - plain & $\mathbf{- 0 . 1 1 3 6 4}$ & $\mathbf{0 . 0 0 2}$ \\
& & Area & 7.93208 & $\mathbf{0 . 0 0 5}$ \\
& & Mean altitude & $\mathbf{0 . 6 1 8 2 1}$ & $\mathbf{0 . 0 0 0 6}$ \\
& & Mean slope & -0.02626 & 0.69 \\
& & Closest distance to urban constructions & $\mathbf{0 . 1 6 7 7 8}$ & $\mathbf{0 . 0 1 3}$ \\
& & Closest distance to natural & $\mathbf{0 . 3 9 7 2 0}$ & $\mathbf{0 . 0 0 0 4}$ \\
& & grassland/sclerophyllous vegetation & 0.02220 & 0.20 \\
\hline
\end{tabular}

${ }^{1} p$ value of the linear model; ${ }^{2}$ the difference between the best model and the next in Akaike's information criterion; ${ }^{3}$ the landscape attributes used as predictor variables; ${ }^{4}$ the estimate of the multiple regression; ${ }^{5}$ significance of the variables in the linear model.

Mean compositional dissimilarity was medium among the orchards $\left(b_{j a c}=0.48\right)$, beta diversity patterns were primarily caused by species replacement $\left(b_{j t u}=0.36\right)$ and not species loss $\left(b_{j t u}=0.12\right)$. Mantel and partial Mantel tests showed that beta diversity ( $\left.b_{\mathrm{jac}}\right)$ was positively correlated with environmental distance while geographic distance was not important (Table 2).

Table 2. Results from Mantel and partial Mantel tests, showing correlations of species dissimilarity distance (expressed by $b_{j a c}$ ) with geographical and environmental distance between the olive orchards.

\begin{tabular}{lcc}
\hline & $\boldsymbol{r}^{\mathbf{1}}$ & $\boldsymbol{P}^{\mathbf{2}}$ \\
\hline Geographic distance & 0.1046 & 0.1702 \\
Environmental distance & 0.301 & 0.007 \\
Effect of environmental distance removed & -0.1048 & 0.8555 \\
Effect of geographic distance removed & 0.3011 & 0.006 \\
\hline
\end{tabular}

${ }^{1}$ Spearman correlation coefficient; ${ }^{2}$ statistical significance of Spearman correlations.

\section{Discussion}

Land snail richness in Cretan olive orchards is significantly higher in the hilly agroecological zone, however no significant differences in species richness were detected between organic and conventional orchards. Our results are supported by previous studies regarding soil-dwelling invertebrate diversity in Cretan olive orchards in the area of study [10]. Indeed, land snail richness is higher in intermediate altitudes [25] which can partly explain why the olive orchards in the hilly zone, i.e. in higher altitudes, have more species in comparison to the olive orchards in the plain zone. In addition, another explanation may also lie in the fact that olive orchards in the hilly zone are characterized by the presence of stony micro-habitats, e.g. stony soils and stone walls, which in turn favour species richness (e.g. [26]). The absence of differences in species richness between organic and conventional olive orchards is also in agreement with previous studies [10]. An explanation is that managment practices (e.g. soil, soil vegetatton and olive tree canopy management) and input use (e.g. irrigation water, fertilizer and pesticide use) differ greatatly within the same farming system (see [27]) and thus hamper any potential effect of the farming system on land snails.

Variation in land snail richness of olive orchards was well-explained by a set of predictors related to habitat size, i.e. area, habitat isolation and anthropogenic impact. Our results agree with the general rule that species richness increases with area [28]. It should be noted however, that orchard area alone did not have an effect on species richness, agreeing with a similar study on the relationship of apple orchard size to land snail richness [5]. This may be related to the fact that the olive orchards have similar sizes ranging from 0.003 to $0.083 \mathrm{~km}^{2}\left(0.012 \mathrm{~km}^{2}\right.$ on average). 
The positive effect of the proximity to natural grassland and sclerophyllous vegetation on species richness was also expected. Such habitats include phrygana - maquis vegetation, are common in the Messara plain and host a relatively high number of land snail species (see [29, 30]). Many land snails typical of phrygana - maquis vegetation were commonly found in the olive orchards indicating the connectivity and low degree of isolation between the different habitats (olive orchards and phrygana - maquis vegetation). Also, species such as C. aspersum, E. vermiculata and Rumina saharica Pallary, 1901 are considered anthropophilic (see $[29,30]$ ) and are associated with human settlements, explaining the positive effect of anthropogenic impact on species richness.

Species composition pattern is mainly due to species replacement and not species loss. This is explained as the olive orchards are in close proximity to each other (e.g. the farthest distance between orchards is $13.6 \mathrm{~km}$ ). Environmental factors, i.e. habitat area, isolation and the anthropogenic impact explained only partly species compositional dissimilarity, whereas the geographic distances between the orchards were not significant at all. Indeed, in such a small scale, Cretan land snail fauna can be homogenous (e.g. [31]). Here, land snails associated with the olive orchards include widespread species, e.g. C. aspersum and E. vermiculata, as well as endemic but common species such as P. bathytera.

\section{Conclusions}

The agroecological zone and not the farming system is associated with land snail species richness. This is in agreement with previous findings for invertebrate fauna of Cretan olive orchards in Crete. A combination of landscape attributes explains satisfyingly patterns of species richness and only partly associates with species composition patterns. More species are found in olive orchards with more available micro-habitats, close to natural habitats and human settlements. At the same time, the scale of the study may explain the medium dissimilarity in species composition. This study is a first attempt to evaluate the effect of olive orchard characteristics on land snails, a group not often used in agroecological research. Our findings indicate that land snails may serve as a potential bioindicator and should be considered in future biodiversity assessments of olive orchard agroecosystems.

Acknowledgments: The current study is co-financed by Greece and the European Union (European Social FundESF) through the Operational Programme «Human Resources Development, Education and Lifelong Learning 2014- 2020» in the context of the project "Impact of different management systems and spatial factors on the biodiversity of olive agroecosystems" (MIS 5048171). The survey took place in pilot olive orchards of the LIFE IGIC project (LIFE16 NAT/GR/000575).

Author Contributions: "V.G. and E.K. conceived and designed the sampling design; E.G. performed the samplings; E.G. analyzed the data; E.G. led the writing with substantial contributions from V.G. and E.K."

Conflicts of Interest: "The authors declare no conflict of interest."

\section{Abbreviations}

\section{Appendix A}

List of linear and linear mixed effects models used to assess the effect of landscape attributes on land snail species richness. The eight models had different combinations of parameters and random effects in order to test for a potential effect of management practice and/or agro-ecological zone on species richness.

List of linear and linear mixed effects models used to assess the effect of landscape attributes on land snail species richness. The eight models had different combinations of parameters and random effects in order to test for a potential effect of management practice and/or agro-ecological zone on species richness. Models were built using the commands ' $1 \mathrm{~m}$ ' and 'lmer' of the 'lme4' R package (Bates et al., 
2020). Models were compared via Akaike Information Criterion (AIC). Models differed significantly when $\triangle$ AIC $>2$ (Burnham and Anderson, 2004).

1. $\quad$ lm_area $<-\operatorname{lm}\left(\log \_\right.$richness $\sim \log \_$area $)$

2. $\operatorname{lm} 0<-\operatorname{lm}(\log r i c h n e s s \sim$ man + az + log_area +logaltmean +logslopemean +log_X112_NEAR_DIST +log_X321_323_NEAR_DIST +log_road, data = snails)

3. $\operatorname{lm} 1<-\operatorname{lm}(\log r i c h n e s s \sim \quad \log$ _area +logaltmean +logslopemean +log_X112_NEAR_DIST +log_X321_323_NEAR_DIST +log_road, data = snails)

4. $\operatorname{lm} 2<-\operatorname{lm}(\log r i c h n e s s \sim$ man +log_area +logaltmean +logslopemean +log_X112_NEAR_DIST +log_X321_323_NEAR_DIST +log_road, data = snails)

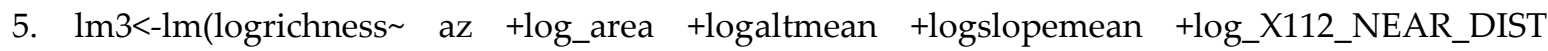
+log_X321_323_NEAR_DIST +log_road, data = snails)

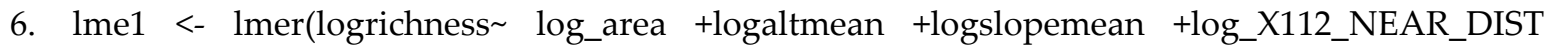
+log_X321_323_NEAR_DIST +log_road + (1 I man $)+(1$ laz $)$, data = snails $)$

7. lme2 <- lmer(logrichness log_area +logaltmean +logslopemean +log_X112_NEAR_DIST +log_X321_323_NEAR_DIST +log_road + (1 I man), data = snails $)$

8. $1 \mathrm{lme} 3<-$ lmer(logrichness log_area +logaltmean +logslopemean +log_X112_NEAR_DIST +log_X321_323_NEAR_DIST +log_road + (1 l az), data = snails $)$

Table A1. List of models in order of highest AIC.

\begin{tabular}{lcc} 
Model & Degrees of Freedom & AIC \\
\hline $\operatorname{lm} 0$ & 10 & -54.181096 \\
$\operatorname{lm} 3$ & 9 & -50.392709 \\
$\operatorname{lm} 2$ & 9 & -33.017370 \\
$\operatorname{lm} 1$ & 8 & -31.484617 \\
$\operatorname{lm} \_$area & 3 & -24.556689 \\
$\operatorname{lm} 33$ & 9 & -15.299324 \\
$\operatorname{lm} 1$ & 10 & -14.101058 \\
$\operatorname{lm} 22$ & 9 & -7.914868 \\
\hline
\end{tabular}

\section{References}


1. Martin, L.J.; Blossey, B; Ellis E. Mapping where ecologists work: biases in the global distribution of terrestrial ecological observations. Front Ecol Environ 2012, 10, 195-201, DOI: 10.1890/110154.

2. Biaggini, M.; Consorti, R.; Dapporto, L.; Dellacasa, M.; Paggetti, E.; Corti, C. The taxonomic level order as a possible tool for rapid assessment of Arthropod diversity in agricultural landscapes. Agric. Ecosyst. Environ. 2007, 122, 183-191, DOI: 10.1016/j.agee.2006.12.032.

3. Heldbjerg, H.; Sunde, P.; Fox, A.D. Continuous population declines for specialist farmland birds 1987-2014 in Denmark indicates no halt in biodiversity loss in agricultural habitats. Bird Conserv. Int. 2018, 28, 278292, DOI: 10.1017/S0959270916000654.

4. Benton, T.G.; Vickery, J.A.; Wilson, J.D. Farmland biodiversity: is habitat heterogeneity the key? Trends Ecol. Evol. 2003, 18, 182-188, https://doi.org/10.1016/S0169-5347(03)00011-9.

5. Bailey, D.; Schmidt-Entling, M.H.; Eberhart, P.; Herrmann, J.D.; Hofer, G.; Kormann, U.; Herzog, F. Effects of habitat amount and isolation on biodiversity in fragmented traditional orchards. J. Appl. Ecol. 2010, 47, 1003-1013, DOI: 10.1111/j.1365-2664.2010.01858.x

6. Kormann, U.; Rosch, V.; Batary, P.; Tscharntke, T.; Orci, K.M.; Samu, F.; Scherber, C. Local and landscape management drive trait-mediated biodiversity of nine taxa on small grassland fragments. Divers Distrib 2015, 21, 1204-1217, DOI: 10.1111/ddi.12324.

7. Kabourakis, E.M. Code of practices for ecological olive production systems. Olivae 1999, 77, 46-55.

8. Volakakis, N.G.; Eyre, M.D.; Kabourakis, E.M. Olive fly Bactrocera oleae (Diptera, Tephritidae) activity and fruit infestation under mass trapping in an organic table olive orchard in Crete, Greece. J. Sustain. Agric. 2012, 36, 683-698, DOI: 10.1080/10440046.2012.672377.

9. Gkisakis, V.D.; Kollaros, D.; Bárberi, P.; Livieratos, I.C.; Kabourakis, E.M. Soil arthropod diversity in organic, integrated, and conventional olive orchards and different agroecological zones in Crete, Greece. Agroecol. Sustain. Food 2015, 39, 276-94, DOI: 10.1080/21683565.2014.967440.

10. Gkisakis, V.D.; Volakakis, N.; Kollaros, D.; Bárberi, P.; Kabourakis, E.M. Soil arthropod community in the olive agroecosystem: Determined by environment and farming practices in different management systems and agroecological zones Agric. Ecosyst. Environ. 2016, 218, 178-189, DOI: 10.1016/j.agee.2015.11.026.

11. Gkisakis, V.D.; Bárberi, P.; Kabourakis, E.M. Olive canopy arthropods under organic, integrated and conventional management. The effect of farming practices, climate and landscape. Agroecol. Sustain. Food. 2018, 42, 843-858, DOI: 10.1080/21683565.2018.1469066.

12. Solomou, A.; Sfougaris, A. Comparing conventional and organic olive groves in central Greece: plant and bird diversity and abundance. Renew. Agric. Food Syst. 2011, 26, 297-316, DOI: 10.1017/S1742170511000111

13. Gonçalves, M.F.; Pereira, J.A. Abundance and diversity of soil arthropods in the olive grove ecosystem. J. Insect Sci. 2012, 12, 1-14, DOI: 10.1673/031.012.2001.

14. Knop, E.; Herzog, F.; Schmid, B. Effect of Connectivity Between Restoration Meadows on Invertebrates with Contrasting Dispersal Abilities. Restor. Ecol. 2011, 19, 151-159. DOI: 10.1111/j.1526-100X.2010.00737.x.

15. Götmark, F.; von Proschwitz, T.; Niklas, F. Are small sedentary species affected by habitat fragmentation? Local vs. landscape factors predicting species richness and composition of land molluscs in Swedish conservation forests. J. of Biogeogr. 2008, 35, 1062-1076, DOI: 10.1111/j.1365-2699.2008.01882.x

16. Welter-Schultes, F. European non-marine molluscs, a guide for species identification, 1st ed.; Planet Poster Editions: Göttingen, Germany, 2012; p. 757.

17. Jeanneret, P; Schüpbach, B.; Luka, H. Quantifying the impact of landscape and habitat features on biodiversity in cultivated landscapes. Agric. Ecosyst. Environ. 2003, 98, 311-320, DOI: 10.1016/S01678809(03)00091-4.

18. Butler, S.J.; Brooks, D.; Feber, R.E.; Storkey, J.; Vickery, J.A.; Norris, K. A cross-taxonomic index for quantifying the health of farmland biodiversity. J. Appl. Ecol. 2009, 46, 1154-1162. DOI: 10.1111/j.13652664.2009.01709.x

19. Quinn, G.P.; Keough, M.J. Experimental design and data analysis for biologists, Cambridge University Press: Cambridge, UK, 2002; p. 537.

20. Bates, D.; Maechler, M.; Bolker, B.; Walker, S. Fitting Linear Mixed-Effects Models Using lme4. J. Stat. Softw. 2015, 67, 1-48. DOI: 10.18637/jss.v067.i01.

21. Baselga, A. Partitioning the turnover and nestedness components of beta diversity. Glob. Ecol. Biogeogr. 2010, 19, 134-143. DOI: 10.1111/j.1466-8238.2009.00490.x. 
22. Baselga, A. 2012 The relationship between species replacement, dissimilarity derived from nestedness, and nestedness. Glob. Ecol. Biogeogr. 21: 1223-1232 DOI:

23. Baselga, A.; Orme, D.; Villeger, S.; De Bortoli, J; Leprieur, F.; Logez, M. 2020. betapart: Partitioning Beta Diversity into Turnover and Nestedness Components. $\mathrm{R}$ package version 1.5.2. https://CRAN.Rproject.org/package=betapart.

24. Oksanen, J.; Guillaume Blanchet, F.; Friendly, M.; Kindt, R.; Legendre, P.; McGlinn, D.; Minchin, P.R; O'Hara, R.B.; Simpson, G.L.; Solymos, P.; Henry, M.; Stevens, H.; Szoecs E.; Wagner H. 2020. vegan: Community Ecology Package. R package version 2.5-7. https://CRAN.R-project.org/package=vegan.

25. Hausdorf, B. Latitudinal and altitudinal diversity patterns and Rapoport effects in north-west European land snails and their causes. Biol. J. Linn. Soc. Lond. 2006, 87, 309-323. DOI: 10.1111/j.1095-8312.2006.00580.x.

26. Kemencei, Z.; Farkas, R.; Páll-Gergely, B.; Vilisics, F.; Nagy, A.; Hornung, E.; Sólymos, P. Microhabitat associations of land snails in forested dolinas: implications for coarse filter conservation. Community Ecol. 2014, 15, 180-186, DOI: 10.1556/ComEc.15.2014.2.6.

27. Bengtsson, J.; Ahnström, J.; Weibull, A.C. The effects of organic agriculture on biodiversity and abundance: a meta-analysis. J. Appl. Ecol. 2005, 42, 261-269, DOI: 10.1111/j.1365-2664.2005.01005.x.

28. MacArthur, R.H.; Wilson, E.O. The Theory of Island Biogeography. Princeton University Press, Princeton, NJ, USA, 1967.

29. Cameron, R.A.D; Mylonas, M.; Triantis, K.; Parmakelis, A.; Vardinoyannis, K. Land-snail diversity in a square kilometre of Cretan maquis: modest species richness, high density and local homogeneity. J. Molluscan Stud. 2003, 69, 93-99, DOI: 10.1093/mollus/69.2.93.

30. Cameron, R.A.D; Mylonas, M.; Vardinoyannis, K. Local and regional diversity in some Aegean land snail faunas. J. Molluscan Stud. 2000, 66, 131-142. DOI: 10.1093/mollus/66.2.131.

31. Hausdorf, B.; Sauer, J. Revision of the Helicellinae of Crete (Gastropoda: Hygromiidae). Zool. J. Linn. Soc. 2009, 157, 373-419. DOI: 10.1111/j.1096-3642.2008.00504.x.

(C) 2020 by the authors; licensee MDPI, Basel, Switzerland. This article is an open access article distributed under the terms and conditions of the Creative Commons by Attribution (CC-BY) license (http://creativecommons.org/licenses/by/4.0/). 